\title{
Tangence
}

Robbert Fortin, Je vais à la convocation à ma naissance, Sudbury/Trois-Rivières, Prise de Parole/Écrits des Forges, 1997, $122 \mathrm{p}$.

\section{Roger Chamberland}

Numéro 56, décembre 1997

Postures scripturaires dans la littérature franco-ontarienne

URI : https://id.erudit.org/iderudit/025962ar

DOI : https://doi.org/10.7202/025962ar

Aller au sommaire du numéro

Éditeur(s)

Tangence

ISSN

0226-9554 (imprimé)

1710-0305 (numérique)

Découvrir la revue

Citer ce compte rendu

Chamberland, R. (1997). Compte rendu de [Robbert Fortin, Je vais à la convocation à ma naissance, Sudbury/Trois-Rivières, Prise de Parole/Écrits des Forges, 1997, 122 p.] Tangence, (56), 109-111. https://doi.org/10.7202/025962ar d'utilisation que vous pouvez consulter en ligne.

https://apropos.erudit.org/fr/usagers/politique-dutilisation/ 


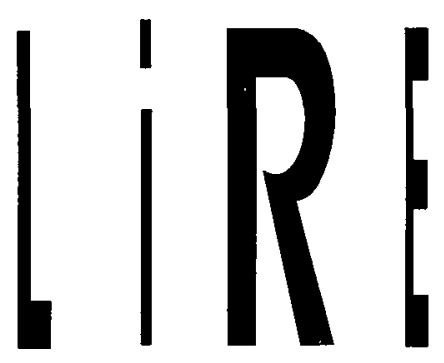

\section{Robbert Fortin, Je vais à la convocation à ma naissance, Sudbury/Trois-Rivières, Prise de Parole/Écrits des Forges, 1997, 122 p.}

Portant le sous-titre révélateur *Poésie-Prose-Combat ", Je vais à la convocation à ma naissance de Robbert Fortin complète une trilogie amorcée en 1994 avec La force de la terre reconnait l'bomme à sa démarche et qui s'est poursuivie l'année suivante avec Peut-il rêver celui qui s'endort dans la gueule des cbiens, recueil qui a d'ailleurs valu à son auteur le Grand Prix du Salon du livre de Toronto. A la différence des recueils précédents, Fortin se dégage d'une parole trop centrée sur son expression et s'engage dans une poésie portée par un vouloir-dire nettement mieux affiché où se développe une pensée et un projet poétiques qui gagne en maturité ce qu'il perd en légèreté. Bien sûr, cela n'enlève rien à la force du propos ni à l'exclusive d'une thématique clairement énoncée dans le titre. Voyons la matière de ce recueil.

Notons en premier lieu que le sous-titre déplace la question du style sur le terrain même du motif sous-jacent au choix de la poésie et de la prose, ce dernier devenant une prose-combat, donc une manière d'écrire subsumant un assaut contre le réel, une façon de prendre le langage à bras le corps pour le faire signifier tout azimuth. Mais le langage n'est-il pas le pont au réel? Un rapport d'existence entre l'individu et ce qui s'agite par devers lui? Fort de ce contexte, "combat marque la lutte incessante entre les règles qui prévalent dans les genres littéraires, mais plus encore le terme soustrait le recueil à la guerre des étiquettes et revendique sa propre énonciation comme mode d'existence et de résolution de conflits avec la réalité. Entre d'autres termes, on peut dire que la poésie, la prose et, ultimement, le combat - 
110

entendu ici comme style - de Robbert Fortin marquent une victoire sur le réel et la mort. Pour lui cela signifie beaucoup car, sans faire dans l'autobiographisme facile, ce livre marque son retour à la vie puisqu'il est l'un de ceux qui ont échappé au sida. Ceci étant dit, il est difficile de passer oütre cette donnée même si le recueil n'en développe pas la problématique à proprement parler.

Dès le premier vers, le poète marque l'état des lieux: "une confrontation a eu lieu/entre le regard et l'essentiel. Dorénavant tout repose sur une vision et une attitude différentes qui décline une esthétique de la chute et de l'obscurité et sa lente remontée vers la lumière. Ainsi devons-nous entendre cette deuxième strophe: aje retombe pêle-mêle dans mes pas/ébloui par une certaine grandeur de la nuit * (p. 7). Fortin radioscopie cette réalité dorénavant transformée par l'angle furtif du regard échappant à l'usuel et au sens commun. Je vais à la convocation à ma naissance marque ce passage à une dimension autre où la perception lui permet de prendre pied dans un monde affranchi de ses contraintes et de ses aliénations, où l'espoir d'un mieux-vivre et d'un mieux-être semblent possibles. Comme cet autre poète qui écrivait: "La lucidité est la blessure la plus rapprochée du soleil * (René Char), Robbert Fortin exprime la douleur qu'implique cette prise de conscience et souligne à juste titre le caractère aléatoire et l'arbitraire de sa démarche: "comment donner à lire/celui que je suis/celui que je me crois être/celui que je voudrais qu'on me croie être ( (p. 14). La poésie n'est possible qu'à ce titre et, là encore, le poète affirme son rapport au texte poétique sans perdre de vue le fait que l'écriture sera toujours en-deça de la démonstration de la preuve d'exister: "la main renversée comme une aile sous un livre/j'ai conscience d'être appelé dans ces poèmes/à la convocation d'un espace sans nom/j'intercepte un rayon lumineux sur la vitre/je ressens l'urgence d'accompagner l'écriture* (p. 16). Fortin pousse encore plus loin et place en opposition les dyades intuition/instinct et raison/logique afin d'être au plus près d'une parole immédiate et sensible puisque c'est là, et seulement là, que réside le sens véritable de toutes choses: "c'est avec toi mon instinct/que je veux répondre/aux ennemis de la paix concrète/aux gisants de la preuve parfaite * (p. 27).

Ce qui compte le plus dans cette poésie, ce n'est pas le point d'arrivée ou l'aboutissement d'une démarche mais cette errance rhizomatique permettant la libre circulation des percepts et des 
affects ("moi je tourne sans but particulier j'écris je nais"p. 108). Le poète s'inscrit dans une territorialité multiple allant ainsi du plus grand au plus petit, d'un cosmos mystérieux et rempli de secrets à une ville tout en trompe-l'œil qui n'offre plus le même intérêt que jadis : *je me jette devant l'écriture/l'œil fauve le ventre blanchâtre/rebondissant fléché d'audace/dans l'immensitude de mon pays d'Amérique/Montréal file cheap/dans ses promesses d'abondance/mais mon cœur fruit rouge/renaît des cycles dénoués. ( $p$. 37). L'illustration même de la couverture intitulée Flying out of this world. S'envoler ailleurs, une œuvre de l'auteur qui est également artiste multidisciplinaire, prend tout son sens au fur et à mesure que progresse la lecture. Cette chemise volant sur un fond de ciel bleu nuit possède la légèreté de l'être ou de l'ange qui va et vient au gré des courants et des vents. Ce recueil marque précisément la fin de la Trilogie de l'Amérique et de l'Ailleurs, mais plus encore il clôt un parcours poétique où l'évidence de la mort bouleverse la nature même de tous les rapports avec le réel. À la fois résurrection et renaissance, Je vais à la convocation à ma naissance devient le lieu de ce double accomplissement et apparait comme un rite de passage vers autre chose que Robbert Fortin nous annonce dans sa dernière strophe: - le présent exige tout de $\mathrm{moi} / \mathrm{mes}$ actes et mes pensées dialoguent/avec l'invisible. (p. 122). L'expérience de la poésie prend tout son sens dans ce recueil qui possède la densité et l'exigence d'une parole qui émerge de la douleur de la mort.

Roger Chamberland 